\title{
Pharmaceutical Quality/CMC Container Type Terminology
}

National Cancer Institute

\section{Source}

National Cancer Institute. Pharmaceutical Quality/CMC Container Type Terminology. NCI Thesaurus. Code C133853.

A category of terminology used to qualify the information pertaining to container types in the framework of the Pharmaceutical Quality/Chemistry, Manufacturing and Controls documents. 